\title{
Estratégias de suporte organizacional para processos de aprendizagem no contexto do futebol ${ }^{*}$
}

\author{
Ramiro Zinder da Silval \\ Universidade Estácio de Sá \\ Narbal Silva ${ }^{2}$ \\ Universidade Federal de Santa Catarina
}

O compartilhamento das aprendizagens individuais é um fenômeno que pode ser facilitado quando existe, na estrutura da organização, estratégias de suporte para esses processos. A mesma realidade é presente no clubes de futebol que deixaram de ser apenas locais recreativos para se tornarem empresas. Sendo assim, o objetivo desta análise teórica é caracterizar as estratégias de suporte organizacional para processos de aprendizagem no contexto do futebol. Trata-se de uma pesquisa bibliográfica no qual são revisados conceitos sobre as organizações de aprendizagem e a aprendizagem organizacional para relacionar estes conceitos com as práticas de suporte organizacional oferecidas pelos clubes de futebol. Embora existam poucos estudos cujo objeto de estudo é o fenômeno da aprendizagem no contexto futebolístico, é possível concluir que os clubes possuem estratégias específicas para facilitar a aprendizagem,
The sharing of individual learning is a phenomenon that can be facilitated when there is, in the structure of the organization, strategies to support these processes. The same situation is present in the soccer teams that are no longer just local entertainment to become businesses. Therefore, the objective of this theoretical analysis is to characterize the strategies to support organizational learning processes in the soccer context. This article is a bibliographical research in which concepts are reviewed on learning organizations and organizational learning to relate these concepts to the practice of organizational support provided by soccer clubs. Although there are few studies in which the object of study is the phenomenon of learning in soccer context, is possible to conclude that the clubs have specific strategies to facilitate learning, however,

\footnotetext{
* Organizational support strategies to learning processes in soccer context

- Mestre em Linguística pela Universidade Federal de Santa Catarina, Coordenador do curso de especialização em Psicologia Organizacional e do Trabalho da Universidade Estácio de Sá, Florianópolis, SC. Endereço para correspondências: Rua Vento Sul, 624, Campeche, Florianópolis, SC, 88063-070 (zinder@edu.estacio.br).

${ }^{2}$ Mestre em Administração e Doutor em Engenharia de Produção pela Universidade Federal de Santa Catarina. Professor do Programa de Pós-Graduação em Psicologia da Universidade Federal de Santa Catarina, Florianópolis, SC (narbal@cfh.ufsc.br).
} 
entretanto, este não é o único fator que contribui para alavancar tal fenômeno.

Palavras-chave: Suporte organizacional - Aprendizagem - Futebol Psicologia dos esportes - Atletas this is not the only factor that contributes to leverage this phenomenon.

Keywords: Organizational support Learning - Soccer - Sports psychology - Athletes

\title{
Introdução
}

\begin{abstract}
aprendizagem organizacional é construída, em um primeiro momento, de Aforma individual, com as experiências de vida, na qual estão incluídas aprendizagens formais e informais adquiridas. Portanto, parece relevante compreender que, antes de qualquer modo de aprendizagem compartilhada, é necessário levar em conta as aprendizagens individuais.
\end{abstract}

Em suas obras, Tsang (1997) e Bastos, Gondim e Loiola (2004) estabeleceram uma classificação em três níveis de análise para fenômeno da aprendizagem: o individual, o grupal e o organizacional. O nível individual corresponde às aprendizagens adquiridas pelo indivíduo ao longo de sua vida, resultado das experiências. A aprendizagem individual depende da percepção, da inteligência, da experiência e das necessidades e motivações de cada um. Na perspectiva de estudo de Argyris e Schön (1978) e Kim (1998), os grupos são considerados elos fundamentais de mediação entre a aprendizagem individual e a aprendizagem organizacional.

O processo de aprendizagem grupal caracteriza-se pelo compartilhamento das aprendizagens individuais. Além disso, o compartilhamento de valores também é significante, na medida em que permite ao grupo o estabelecimento de regras em comum, aceitas pelos seus membros como aspectos norteadores do desempenho. A interação gera conhecimento mútuo e visualização de pontos comuns que servirão de base para a elaboração de normas coletivas, tácitas e explícitas (MOSCOVICI, 2001).

O futebol é um exemplo de esporte coletivo em que o compartilhamento de valores é fundamental para o sucesso de um time. A importância de tal sucesso ganhou maior proporção a partir da década de 1990, quando este esporte adquiriu uma dimensão de negócio lucrativo, no momento em que muitos clubes deixaram de ser apenas locais recreativos para se tornarem empresas. Fatores como a Lei Pelé, sancionada em 1998; a Nova Lei Pelé, de 2001 e o Estatuto do Torcedor, aprovado em 2003, geraram mudanças nos clubes. Dentre as mudanças, talvez a mais notável seja a profissionalização da gestão do futebol, ou seja, os dirigentes deixaram de ser os torcedores ilustres que chegavam a investir seu próprio dinheiro no clube e passaram a ser gestores profissionais, em geral, com experiências bem sucedidas no ramo espresarial (LEONCINI \& SILVA, 2005). 
No primeiro Relatório Final do Fórum de Discussão Permanente de Políticas do Esporte, construído pelo Núcleo de Estudo em Esporte (NEE) da Fundação Getúlio Vargas (FGV), consta que, a partir da década de 1990, houve a necessidade de adequação aos processos envolvidos no futebol dos quais destacam-se: investimento da mídia televisa nos jogos de futebol, transações de altos valores com o mercado exterior e o aumento do número de competições disputadas por clubes. Dois anos mais tarde, no Relatório publicado por Zouain e colaboradores (2006), evidenciou-se o planejamento dos clubes para uma gestão profissional como fonte de resultados positivos e lucrativos, o investimento em estádios para a geração de emprego e de renda e "a formação de mão-de-obra qualificada, necessária em um setor em que se pretende, mesmo em longo prazo, buscar a excelência" (p. 731). Diante das recomendações presentes nos dois relatórios, todos esses fatores levaram os clubes a modernizar sua administração, deixando o amadorismo e proporcionando um modelo de gestão profissional.

Gerenciar de forma profissional, pressupõe atenção às diversas variáveis que influenciam as organizações. Dentre tais variáveis, a compreensão das relações entre aprendizagens individuais, grupais e aprendizagens nas organizações destaca-se como aspecto relevante. Para De Geus (1998), este fator corresponde a uma das vantagens competitivas das organizações frente aos desafios impostos pela contemporaneidade como, por exemplo, a globalização, a competitividade e as novas tecnologias. A compreensão da aprendizagem como fator relevante para a melhoria do desempenho das organizações é evidenciada por autores consagrados como Argyris e Schön (1978), Kolb (1984), Garvin (1993, 2002, 2008) e Senge (2002). Com base no exposto, torna-se relevante, nesta análise teórica, caracterizar as estratégias de suporte organizacional para processos de aprendizagem no contexto do futebol.

\section{Organizações com suporte para os processos de aprendizagem}

Os estudos sobre as organizações de aprendizagem ganharam evidência ao final da década de 1980 e na década de 1990 devido às mudanças de ordem político-econômica e tecnólogica. Nesse período, dois fenômenos principais contribuiram para que o conhecimento fosse colocado em lugar de destaque no ambiente organizacional: a ausência de barreiras político-econômicas na transação entre países - processo conhecido como globalização que permitiu a abertura de novos mercados para as organizações e as transformações que agilizaram a transmissão de informações como os telefones celulares e a internet, que provocaram uma demanda maior de conhecimentos necessários para a consolidação no mercado (FRANCO \& FERREIRA, 2007). 
Tais fenômenos geraram desafios para a competitividade das organizações e, no intuito de superá-los, De Geus (1998) estabeleceu o conceito de tolerância. Este conceito corresponde à flexibilidade, que significa a capacidade de os gestores apresentarem variedades de respostas ao ambiente e, consequentemente, tornar o seu negócio mais competitivo.

Diante desse cenário, as organizações que oferecem, em sua estrutura, suporte aos processos de aprendizagem entre seus empregados são conceituadas de organizações de aprendizagem, ou também, organizações que aprendem. Por vezes, na literatura, constata-se confusão entre tal conceito e as definições de aprendizagem organizacional. As organizações de aprendizagem são objetos de estudos de consultores sobre a transformação organizacional. Os estudos são baseados em experiências práticas bem sucedidas, que são generalizadas para outras organizações. O propósito, neste caso, é demonstrar as estratégias utilizadas para possibilitar o aprendizado de trabalhadores no ambiente corporativo. Já a vertente de estudos sobre a aprendizagem organizacional é caracterizada por pesquisadores acadêmicos que tem como objetivo principal a construção de teorias sobre o fenômeno da aprendizagem para, assim, descrever os fatores associados a tal processo nas organizações de trabalho (TSANG, 1997; BASTOS et al., 2004).

Embora possuam diferenciações conceituais, as organizações de aprendizagem (OA) e a aprendizagem organizacional $(\mathrm{AO})$ apresentam características convergentes. Autores como Tsang (1997), por exemplo, definem as OA como aquelas que conseguem obter estratégias de AO. É recorrente, nas obras sobre a aprendizagem organizacional, como em Bastos e colaboradores (2004) e Abbad e Borges-Andrade (2004), referirem-se às organizações que aprendem como uma metáfora. Porém, a expressão é inadequada, visto que a metáfora é uma figura de linguagem de comparação e não um recurso de personificação.

Em 1988, Aries De Geus - então diretor de planejamento da Royal Dutch/Shell - apresentou um artigo intitulado "Planning as learning" na revista Harvard Business Review. Embora o autor não tivesse reconhecimento acadêmico-científico na época, o artigo causou repercussão ao tratar a aprendizagem no ambiente corporativo como a única vantagem competitiva do futuro (SENGE, 1999). Anos mais tarde, no livro que foi originado do artigo, De Geus (1998) revela que uma empresa considerada saudável e que deseja se manter no mercado por longos anos deve estimular a aprendizagem entre os trabalhadores e, além disso, permitir o compartilhamento de valores para que todos se direcionem para um objetivo em comum. Desta forma, os membros da organização poderão alcançar seus objetivos individuais, como o crescimento profíssional e o reconhecimento, por meio do alcance dos objetivos organizacionais: a manutenção no mercado, o crescimento organizacional e o lucro, por exemplo. 
As organizações que aprendem apresentam características comuns no que se refere ao fato de que os indivíduos se encontram engajados com os processos de aprendizagem. Senge (2002), por exemplo, revela que as organizações que aprendem são organizações nas quais as pessoas ampliam continuamente a capacidade de criar os resultados que realmente desejam, onde ocorre o estímulo de padrões de pensamento novos e abrangentes, em que a aspiração coletiva ganha liberdade e as pessoas aprendem juntas e continuamente. Para que este conceito seja posto em prática, o autor estabelece cinco disciplinas para a sua construção: domínio pessoal, modelos mentais, construção de uma visão compartilhada, aprendizagem em equipe e pensamento sistêmico. O domínio pessoal refere-se ao autoconhecimento e ao aprendizado individual, os modelos mentais correspondem à externalização da visão de mundo e de homem que determina o modo de pensar e agir de cada indivíduo, a construção de uma visão compartilhada ocorre quando as pessoas assumem o comprometimento em alcançar uma aspiração em comum, a aprendizagem em equipe é a capacidade de compartilhar as aprendizagens e convergí-las para o objetivo em comum e, por fim, o pensamento sistêmico norteia todas as disciplinas anteriores e pressupõe a consciência das conexões e consequências de longo prazo (SENGE, 2002).

Os pressupostos e critérios para a construção de organizações que aprendem são de difícil implantação, tanto que Finger e Brand (2001) consideram que a organização de aprendizagem é um ideal, seguindo o pensamento de Senge (2002) que a considera como uma visão. Estes autores destacam, entretanto, que tais organizações correspondem a um movimento no sentido de superar as demandas contemporâneas que exercem pressão sobre as organizações. Uma das formas para se manter em uma economia globalizada e de competitividade entre as organizações, seria o investimento na aprendizagem no ambiente de trabalho.

Embora Senge (2002) admita que todas as organizações aprendem, pois se adaptam na medida em que o ambiente à sua volta se modifica, o que ocorre é que algumas organizações aprendem de forma mais rápida e eficaz que outras. Sendo que o aprendizado ocorre pelas pessoas que compõem a organização, em outras palavras, "as organização só aprendem por meio de indivíduos que aprendem” (p. 167). Tal afirmação corrobora a importância dos processos de aprendizagem individual para as organizações.

As organizações consideradas de aprendizagem possuem estratégias de suporte para que existam espaços de aprendizado entre os empregados, no ambiente de trabalho. A crença de que se pode definir processos normativos que levam a uma aprendizagem acentuada é recorrente nas obras que tratam das organizações de aprendizagem (EASTERBY-SMITH \& ARAÚJO, 2001), 
ou seja, as organizações de aprendizagem possuem políticas direcionadas para a criação, aquisição e transferência de conhecimentos, modificando o comportamento dos indivíduos de maneira a refletir novos conhecimentos e insights (GARVIN, 1993).

A eficácia de tais políticas está vinculada aos processos estabelecidos pela gestão que podem, ou não, orientar os indivíduos para o compartilhamento dessas aprendizagens. Espaços voltados para a aprendizagem, comunicação eficaz, atribuição de funções condizentes com as competências individuais e apoio da gestão, são exemplos de contextos organizacionais que podem facilitar os processos de aprendizagem e a sua transferência (KIM, 1998; ABBAD \& BORGES-ANDRADE, 2004). No entendimento de Garvin (1993), os ambientes que possuem estruturas voltadas para a aprendizagem apresentam cinco atividades necessárias - building blocks -, segundo a classificação:

a) Resolver sistematicamente os problemas - consiste na utilização de métodos científicos, dados empíricos e ferramentas estatísticas para conferir mais precisão na resolução de conflitos;

b) Experimentar - envolve a procura sistemática e a testagem de novos conhecimentos, com base em métodos científicos;

c) Aprender com experiências passadas - corresponde à revisão de experiências de sucesso e de fracasso passadas, para analisar os fatores que levaram a determinados resultados;

d) Aprender com os outros - refere-se ao fato de que é possível obter insights ao observar o comportamento de pessoas externas ao grupo de trabalho, que podem ser, inclusive, concorrentes diretos;

e) Transferir o conhecimento - o conhecimento dever ser compartilhado rapidamente e de forma eficiente para todo o ambiente organizacional.

Algumas organizações possuem as características descritas anteriormente em algum grau de eficácia, mas poucas apresentam resultados satisfatórios. Criar estratégias que ofereçam suporte para estas atividades e integrá-los nas tarefas básicas do cotidiano de trabalho, pode resultar em formas mais eficazes de promover a aprendizagem (GARVIN, 1993).

Em pesquisa realizada em uma empresa de cerâmica no sul do estado de Santa Catarina, Silva (2001) descreveu e interpretou as interfaces entre os pressupostos básicos de cultura e as estruturas de ação orientadas à aprendizagem organizacional, propostas por Garvin (1993). No resultado do estudo é demonstrado que as estruturas de ação foram implementadas com base na cultura organizacional. A resolução sistemática de problemas orientava os princípios de qualidade, na busca pela excelência, ao identificar e corrigir os erros. 
A experimentação era atribuída, principalmente, aos designers que, por sua vez, enfrentavam dificuldades em razão da inexistência de um planejamento mais ordenado. A aprendizagem com experiências passadas, bem como, a aprendizagem com as experiências dos outros são pautadas nos primeiros anos da organização, por meio de práticas bem sucedidas ou erros que serviram de aprendizado. Por fim, em relação às transferências de conhecimento, foram identificadas estratégias como reuniões, murais e programas de treinamento (SILVA, 2001).

Em artigo mais recente, Garvin (2008) elenca mais três estratégias de ação para a construção de uma organização de aprendizagem:

a) Apoio educativo - trabalhadores devem se sentir seguros em questionar estratégias, demonstrar erros cometidos e apresentar pontos de vista particulares, reconhecer o valor de ideias contrárias, assumir riscos e explorar o desconhecido, e possuir tempo disponível para rever os processos organizacionais;

b) Processos de aprendizagem concretos - uma equipe ou uma empresa deve possuir processos formais para generalizar, interpretar e disseminar as informações, experimentar novos processos, explorar a inteligências de outras organizações (benchmarking), de clientes e de novas tendências tecnológicas, identificar e solucionar problemas, e desenvolver habilidades dos empregados; $\mathrm{e}$

c) Liderança que reforce a aprendizagem - os líderes das organizações devem demonstrar vontade de agregar pontos de vista alternativos, sinalizar a importância de organizar tempo para a identificação de problemas, transferência de conhecimento e reflexão dos processos, e engajar ativamente nos processos de escuta e questionamento.

As estruturas de ação demonstradas por Garvin $(1993,2008)$ servem de modelo para a construção de uma organização de aprendizagem, porém, de acordo com cada cultura organizacional, poderão ser estabelecidos processos diversificados.

Identificadas as características das organizações de aprendizagem e suas estruturas que podem facilitar ou restringir esses processos, fica evidente que os fatores de suporte organizacional não correspondem ao único elemento que contribui para o desenvolvimento de uma organização de aprendizagem. Os indivíduos que fazem parte das organizações, por meio dos grupos de trabalho, também são os responsáveis pelo aprendizado no ambiente corporativo. Como já foi ressaltado, são as pessoas que iniciam o processo de aprendizagem organizacional, por meio das aprendizagens individuais. 


\section{Modelos de estudo para os processos de aprendizagem nas organizações}

No ambiente corporativo, os movimentos de aprendizagem são constantes devido, entre outros motivos, aos processos de treinamento e desenvolvimento que os gestores financiam para seus empregados. Entretanto, Argyris e Schön (1978) argumentam que a aprendizagem só ocorre quando novos conhecimentos são traduzidos em diferentes comportamentos que sejam replicáveis nos diversos contextos de uma organização. Seguindo o mesmo conceito, Abbad e Borges-Andrade (2004) entendem que a aprendizagem faz referência a mudanças que ocorrem no comportamento do indivíduo e que são resultantes de sua interação com o contexto.

Dentre os modelos de estudo encontrados na literatura sobre os processos de aprendizagem nas organizações, destacam-se os construídos por Argyris e Schön (1978), Kolb (1984), Garvin (2002) e Kiehl (2008). Os primeiros desenvolveram a teoria dos circuitos de aprendizagem, no qual o circuito simples de aprendizagem limita-se a detectar os erros nas ações organizacionais e corrigi-los para que, assim, sejam propostas novas ações. $O$ circuito duplo de aprendizagem, além de possuir as etapas do circuito simples, ainda promove mudanças nos valores fundamentais da organização. O modelo de Kolb (1984) trata da aprendizagem vivencial, que, segundo o autor, a aprendizagem é " $[\ldots]$ o processo em que o conhecimento é criado por meio da transformação da experiência" (p. 83). Este modelo é caracterizado por um ciclo quadrifásico envolvendo os seguintes estágios em sequência: a experiência concreta, a observação reflexiva, a conceituação abstrata e a experimentação ativa. A passagem pelas experiências concretas (vivência) fornece informações para observação e reflexão por parte do indivíduo. A construção de conceitos e generalizações ocorre na medida em que são identificadas linhas comuns de pensamento. Por fim, a experimentação ativa acontece quando situações vivenciadas impulsionam as pessoas para a procura de novas experiências concretas, constituindo, assim, outro ciclo de aprendizagem (KOLB, 1984).

No modelo de aprendizagem nas organizações construído por Garvin (2002) são estabelecidos três estágios: a aquisição de informações, a interpretação de informações e a aplicação de informações. Para o autor, a aquisição de informações é relativamente fácil em uma sociedade repleta de tecnologias voltadas para a comunicação, porém, o desafio consiste em filtrar as informações relevantes e irrelevantes. Não basta somente adquirir informações relevantes, é preciso interpretá-las, ou seja, traduzir os eventos, desenvolver modelos para sua compreensão, extrair seus significados e montar esquemas conceituais. Por fim, a aplicação refere-se ao agir, visto que a aprendizagem tende a ser afetiva quando existe uma ação orientada pelo conhecimento. 
A aprendizagem ancorada em emoções, tradução do termo locker room learning (LRL), é um modelo construído por Kiehl (2008) no qual se pressupõe que os afetos são responsáveis pela forma como os indivíduos aprendem nas organizações em processos de mudança. A estrutura do processo de aprendizagem ancorada em emoções assemelha-se ao modelo de Kolb (1984), por se constituir de um ciclo quadrifásico. A LRL inicia com a crença, posteriormente avança para a escolha, passa para o engajamento e para a última etapa que é a avaliação. De acordo com tal estrutura, a passagem da etapa de crença para a escolha passa por processos intrapessoais, valores e mapas mentais comuns a cada indivíduo. A transição entre a escolha e o engajamento ocorre pelo vínculo que o indivíduo faz e o desejo de se adaptar ao novo contexto de mudança. Em seguida, ocorre a passagem do "engajamento" para a "avaliação", que é caracterizada como um processo coletivo e interpessoal, para que, ao final do ciclo, aconteçam os questionamentos que permitam ao indivíduo continuar acreditando no processo ou não.

$\mathrm{Na}$ já mencionada classificação do fenômenos da aprendizagem nos níveis individual, grupal e organizacional (TSANG, 1997; BASTOS et al., 2004) vale ressaltar que, ao considerar o processo de aprendizagem individual, é relevante perceber o contexto no qual ele está inserido e suas relações com o meio. Desta forma, percebe-se a dificuldade em delimitar quando inicia e quando termina cada nível de análise (RIGGENBACH, 2007).

\section{Construção da aprendizagem organizacional por meio da aprendiza- gem individual}

O nível individual corresponde às aprendizagens adquiridas pelo indivíduo ao longo de sua vida, resultado das experiências. A aprendizagem individual depende da percepção, da inteligência, da experiência e das necessidades e motivações de cada um. Depende, ainda, do ambiente de aprendizagem. Caracteriza-se por uma racionalidade e por uma especificidade individuais e resulta em mudanças cognitivas e/ou comportamento individual. (FRANCO \& FERREIRA, 2007). Para Abbad e Borges-Andrade (2004), por exemplo, o conceito de aprendizagem envolve, além de aquisição e retenção, a generalização e a transferência. Retenção corresponde ao tempo em que as aprendizagens continuam sendo aplicadas no trabalho. Generalização é entendida como a capacidade de reproduzir habilidades e comportamentos adquiridos em um contexto de trabalho para situações diferentes daquelas em que houve o aprendizado. Transferência é constituída por mecanismos pelos quais ocorrem "[...] a transmissão de conhecimentos e disseminação de novas tecnologias de trabalho" (p. 239-240). 
Nos estudos acadêmicos sobre os processos de aprendizagem individual, constam classificações quanto à natureza do fenômeno, que compreende os conceitos de aprendizagem formal e informal (não formal). Autores como Carvalho (1999), Shugurensky (2000) e Gohn (2006) estabelecem que a aprendizagem formal possui conteúdos previamente planejados para atingir objetivos específicos e resultados esperados. Este tipo de aprendizagem ocorre em estruturas institucionais como escolas e universidades, além de seguir uma hierarquia de ensino-aprendizagem que, no Brasil, corresponde ao ensino fundamental, médio, superior e de pós-graduação. A aprendizagem informal, conforme os mesmos autores, ocorre diariamente, ao longo da vida de uma pessoa, em espaços não-formais de aprendizado. Tal fenômeno consiste na aquisição de conhecimento por meio da experiência cotidiana e influência da rede social, no qual a pessoa está inserida.

Apesar das diferenças demonstradas pelos autores referenciados anteriormente, Malcolm e colaboradores (2003) e Antonello (2005) contestam as definições apresentadas, por entenderem que as conceituações são fronteiriças, que existem elementos significativos da aprendizagem formal em situações informais, e elementos de informalidade em situações formais. Os pesquisadores concluem, portanto, que as aprendizagens formais e informais estão indissoluvelmente interrelacionadas.

A aprendizagem individual pode ser entendida como a origem da aprendizagem organizacional, na medida em que se entende que não são as organizações que aprendem, mas sim, as pessoas. Zanelli e Silva (2008) revelam que a aprendizagem individual pode estar fragmentada e desconectada dos propósitos organizacionais, como também, pode estar difundida e compartilhada em outras instâncias da organização. Os autores esclarecem, também, que é por meio das aprendizagens dos indivíduos que se chega à aprendizagem organizacional.

Nos primeiros estágios de existência de algumas organizações, a aprendizagem organizacional é frequentemente sinônimo de aprendizagem individual, pois tais organizações podem consistir em um pequeno grupo de pessoas em uma estrutura mínima (KIM, 1998). Outro raciocínio possuem Zanelli e Silva (2008), que não entendem como sinônimos, mas que a aprendizagem organizacional ocorre por meio de atores individuais cujas ações estão baseadas em modelos mentais compartilhados.

Mas, de que modo as aprendizagens passam do nível individual para o nível organizacional? Na perspectiva de estudo de Argyris e Schön (1978) e Kim (1998), os grupos são considerados elos fundamentais de mediação entre a aprendizagem individual e a aprendizagem organizacional. É o compartilhamento dos conhecimentos que permite que as aprendizagens sejam elevadas ao nível da organização. Este raciocínio admite que o processo de aprendizagem grupal caracteriza-se pelo compartilhamento das aprendizagens individuais e, 
talvez por isso, não existam muitos estudos empíricos sobre a aprendizagem grupal. Tal fenômeno pode estar associado à transferência de conhecimentos ou ao compartilhamento em si. Uma das poucas referências sobre a aprendizagem grupal é encontrada em Cook e Yanow (1996, apud BASTOS et al., 2004; p. 384), que interpretam este fenômeno como a "[...] aquisição, sustentação e mudança de significados intersubjetivos através da expressão e transmissão de ações coletivas do grupo".

Outra referência sobre a aprendizagem compartilhada é denominada por Senge (2002) como aprendizagem em equipe - uma de suas cinco disciplinas para a construção de uma organização que aprende - que constitui um "processo de alinhamento e desenvolvimento da capacidade da equipe criar os resultados que seus membros realmente desejam" (p. 263). A construção da aprendizagem em equipe é baseada nas disciplinas domínio pessoal e visão compartilhada. Além disso, Senge (2002) descreve outras características para a formação deste tipo de aprendizagem:

a) a necessidade de pensar reflexivamente - de modo a utilizar o potencial de muitas mentes para que a inteligência da equipe seja superior à inteligência de cada membro;

b) necessidade de ação inovadora e coordenada - significa uma "confiança operacional", ou seja, a consciência de membros da equipe para complementar ações de outros membros;

c) papel dos membros da equipe em outras equipes - uma equipe que aprende estimula continuamente outras equipes a aprender;

d) utilização do pensamento sistêmico para lidar de forma criativa contra dificuldades - diversificar os métodos para resolução de conflitos existentes na equipes que, de alguma forma, impeçam a aprendizagem;

e) exigência prática - o processo de aprendizagem é um movimento contínuo entre prática e desempenho. Não há aprendizagem em equipe sem treino ou ensaio.

Dentro de um grupo ou de uma equipe, a criação e manutenção de construções sociais comuns à realidade da organização, só podem acontecer, se os membros reconhecem a necessidade de possíveis mudanças, comunicando-as e discutindo-as com os outros membros (FRANCO \& FERREIRA, 2007). É este movimento que permite com que as aprendizagens individuais compartilhadas pelas pessoas sejam alavancadas para o nível da organização. Portanto, o que efetiva a aprendizagem é a eficácia com que os indivíduos transferem seus aprendizados para a coletividade e para a organização, de modo a inseri-los e legitimá-los na estrutura organizacional (ZANELLI \& SILVA, 2008). 
A aprendizagem organizacional é definida por Kim (1998) como "[...] o aumento da capacidade de uma organização realizar ações eficazes". Este tipo de aprendizagem compreende o modo pelo qual as pessoas atribuem significados às suas experiências de trabalho (EASTERBY-SMITH \& ARAÚJO, 2001). Cabe salientar, que o fato de os indivíduos estarem aprendendo intensamente não significa, obrigatoriamente, que a organização possui estratégias orientadas para a aprendizagem eficaz. Em uma organização de aprendizagem otimizada, alguns podem não aprender com a mesma intensidade dos demais, ou não aprender aquilo que é significativo para os objetivos organizacionais.

Os comportamentos organizacionais podem ser voltados para a aprendizagem quando apresentam quatro condições necessárias, segundo a classificação de Garvin (2002):

a) reconhecer e aceitar as diferenças;

b) buscar novas formas de pensar e novas fontes de informações;

c) proporcionar feedback oportuno e imparcial; e

d) aceitar os erros, enganos e ocasionais fracassos como preço da melhoria.

Para o referido autor, o reconhecimento das diferenças é fundamental para o exercício da aprendizagem, pois, sem ela, "[...] a letargia e a inércia entram em cena, e os esquemas e estruturas vigentes permanecem atuantes" (p. 38). As diferenças contribuem, portanto, com a estimulação de novas idéias, isto é, novas formas de pensar e novas fontes de informações. Com o feedba$c k$ é possível assimilar novas observações, comparar com os resultados esperados e, assim, identificar deficiências mais rapidamente. Por fim, a tolerância aos erros está fundamentada na construção de um ambiente "psicologicamente seguro", ou seja, ambientes caracterizados por oportunidades de treinamento, apoio e encorajamento para superar temores e vergonhas associadas aos erros, recompensas pelos esforços, normas que legitimem a ocorrência de erros e normas que recompensem o pensamento inovador.

As premissas de Garvin (2002) são endossadas pela aprendizagem ancorada em emoções, modelo teórico já explicado anteiormente, no qual se pressupõe que os afetos são responsáveis pela forma como os indivíduos aprendem nas organizações em processos de mudança.

As estruturas de ação demonstradas por Garvin $(1993,2008)$ servem de modelo para a construção de uma organização de aprendizagem, porém, de acordo com cada cultura organizacional, serão estabelecidos processos diversificados. É o caso dos clubes de futebol, que possuem um produto específico e, portanto, podem criar outros métodos para alavancar processos de aprendizagem entre seus atletas. 
Estratégias de suporte organizacional para processos de aprendizagem no contexto do futebol

\section{Suporte organizacional e aprendizagem no contexto do futebol}

As organizações, cujo produto é o futebol, são definidas como instituições político-administrativas responsáveis pela organização de uma equipe que compete com outras. Sendo assim, os clubes precisam integrar os membros de sua comunidade afetiva - isto é, pessoas que possuem emoções vinculadas ao time, como, por exemplo, os torcedores - e preservar a memória da instituição, por meio da criação de símbolos de identificação, de conquistas importantes etc. (DAMO, 2008).

As estratégias de gestão de um clube podem ser classificadas em três níveis, conforme o entendimento de Leoncini e Silva (2005). O primeiro nível compreende as estratégias competitivas, que são aquelas voltadas para o mercado alvo e prestação de serviços, por exemplo. O segundo nível é a estratégia do negócio que corresponde aos parâmetros de lucro, alavancagem de valor sobre custos, gastos de folha salarial do time, entre outros. O último nível é o da integração entre estratégias e sistema operacional, ou seja, estabelecer práticas de desenvolvimento de pessoas, projetar instalações adequadas às necessidades da equipe e definir procedimentos de aprendizagem. Este último nível pode ser considerado equivalente às estruturas de ação para a aprendizagem, já que apresenta funções semelhantes àquelas estabelecidas por Garvin (1993, 2008), Kim (1998) e Abbad e Borges-Andrade (2004).

Nas competições futebolísticas, tanto os atletas, quanto os membros da comissão técnica podem facilitar o rendimento individual e coletivo ao propiciar um suporte social significativo - formação profissional adequada, boa formação familiar e apoio do grupo de jogadores. O suporte organizacional, por sua vez, corresponde à assistência do departamento de futebol dos clubes aos atletas e comissão técnica (CORRÊA et al., 2002). Entretanto, o departamento de futebol - setor da estrutura organizacional de um clube responsável pelo gerenciamento de atividades ligadas ao time - não é o único responsável em oferecer suporte à equipe. Um time de futebol eficaz depende, em boa parte, da ação da várias áreas do clube, dentre as quais destaca-se os departamentos: administativo, marketing, financeiro, recursos humanos e patrimônio. Quanto mais organizadas estiverem estas áreas que servem de suporte ao futebol, mais tranquilidade terá o departamento técnico para alcançar seus objetivos (BRUNORO \& AFIF, 1997).

No contexto do futebol, Leoncini e Silva (2005), estabelecem três ciclos permanentes de aprendizagem para análise dos processos de mudança nos clubes: as mudanças interempresariais, a aprendizagem estratégica e a aprendizagem organizacional. As mudanças interempresariais são dinâmicas internas ao mercado do futebol que compreendem, por exemplo, o licenciamento da marca de um clube e a criação de parcerias com empresas de venda de ingressos pela internet. As aprendizagens estratégicas e organizacionais determinam o modelo de gestão adotado por uma organização num determinado momento. 
Nesta abordagem, tais aprendizagens, apesar de sua natureza dinâmica, são percebidas como visões de negócio e competências já interiorizadas pela organização ou pelos seus dirigentes (LEONCINI \& SILVA, 2005).

Fica evidente que os fatores de suporte organizacional não correspondem ao único elemento que contribui para o desenvolvimento de uma organização de aprendizagem. Os indivíduos que fazem parte das organizações, por meio dos grupos de trabalho, também são os responsáveis pelo aprendizado no ambiente corporativo. Como já foi ressaltado, são as pessoas que iniciam o processo de aprendizagem organizacional, por meio das aprendizagens individuais.

Corrêa e colaboradores (2002), em estudo realizado com ex atletas, atletas, treinadores e preparadores físicos, descobriram fatores que influenciam na performance de jogadores de futebol e, entre eles, encontram-se aspectos psicológicos, sociais e físicos/táticos. Nas subcategorias apresentadas na pesquisa dos referidos autores, destacam-se fenômenos psicológicos como: motivação, confiança, e preparação mental; suporte social como: aceitação do grupo, contexto familiar de apoio à profissão, e contexto organizacional que apóie o atleta; e aspectos físicos/táticos como: preparação física, aprimoramento dos fundamentos técnicos e táticos, e assimilação do método de trabalho do treinador. Tais elementos identificados pelos autores, principalmente os aspectos táticos, indicam que os processos de aprendizagem são variáveis que auxiliam na constituição da performance individual dos atletas.

Embora os autores supracitados compreendam o contexto organizacional que apóie o atleta como um elemento do suporte social, existe divergência nesta definição, visto que Garvin (1993, 2002), De Geus (1998), Kim (1998) e Senge (2002), por exemplo, consideram este fator como elemento do suporte das organizações (ou estruturas de ação) orientadas à aprendizagem.

No estudo de Szezerbicki e colaboradores (2006) são apresentados indícios de que existem relações entre esse dois fenômenos. Os pesquisadores estudaram a gestão do conhecimento em equipes de alta performance, ao analisar o caso do Clube Atlético Paranaense. O objetivo desta pesquisa foi investigar se existia o desenvolvimento de equipes de alta performance e quais foram os procedimentos adotados para alcançar este objetivo em um clube de futebol. Os autores demonstraram que o clube possuía equipes multidisciplinares que atendiam os atletas de forma integrada, que os profissionais do clube estavam em constante atualização e reciclagem, além do investimento no conhecimento dos atletas por meio de parceria com escolas e instituições de ensino superior que ministravam cursos voltados para a área esportiva. Conforme os autores da pesquisa, as diretrizes da organização estudada pressupõem uma gestão orientada pelo conhecimento que, em decorrência, impulsiona a construção de uma equipe de alto desempenho. 
Outra pesquisa que trata da aprendizagem em times de futebol foi realizada por Corrêa (2004), ao analisar a construção de competências coletivas nos quatro principais times do Rio Grande do Sul por meio de entrevistas com jogadores, técnicos e dirigentes dos clubes, além de observações de treinos e partidas. $\mathrm{O}$ autor da pesquisa identificou que existem alguns fatores responsáveis pelo desempenho satisfatório dos clubes, como atrair os melhores jogadores, contratar bons jogadores, atrair patrocinadores, torcedores, associados e consumidores, e possuir dinheiro suficiente em caixa. Dentre as competências identificadas pelo pesquisador como essenciais aos clubes, destacam-se a capacidade de formar atletas de base (juvenis), formar equipes competitivas, oferecer conforto e segurança em seus estádios, integrar-se e envolver-se com a comunidade. As competências individuais descobertas pelo autor foram categorizadas conforme a função que os sujeitos de pesquisa exerciam no clube (jogador, técnico ou dirigente), sendo que nos atletas foi identificada a "capacidade de desenvolver habilidades táticas, técnicas e físicas maiores que a dos adversários; capacidade de atuar com garra, empenho e motivação; capacidade de compreender e seguir as orientações da comissão técnica; e capacidade de atuar com seriedade" (p. 115).

$\mathrm{Na}$ literatura internacional, Balduck e Buelens (2007) construíram uma pesquisa no futebol belga partindo do conceito de organizações de aprendizagem para analisar a influência da troca de técnicos sobre a performance dos times nos campeonatos da primeira divisão de 1998 até 2003. Os autores concluíram que a troca de treinador nos times que apresentavam desempenhos insatisfatórios no campeonato gerava um impacto positivo em curto prazo, porém, não era a alternativa mais eficiente e eficaz para a melhoria do desempenho dos times, visto que, na análise dos resultados, os clubes que mudavam de técnico apresentavam desempenho inferior aos que mantinham-no. Segundo os autores, os resultados confirmam a teoria das organizações de aprendizagem, em especial, no fato de que é necessário tempo para que ocorram as aprendizagens e, assim, melhorar a performance dos times de futebol.

\section{Conclusão}

Na literatura científica nacional, são raras as pesquisas cujo objeto de estudo é o fenômeno da aprendizagem no contexto futebolístico. Ao considerar que o futebol é um esporte muito difundido no Brasil, é surpreendente a escassa literatura abordando tal perspectiva nesse esporte (MORAES et al., 2004). Entretanto, é possível concluir que os clubes de futebol apresentam estratégias de suporte para os processos de aprendizagem de acordo com a particularidade deste tipo de organização cujo produto é o futebol. 
As estruturas de ação definidas por Garvin $(1993,2008)$ são adequadas aos times de futebol para atender as necessidades específicas dos clubes de futebol. Talvez, o setor chave para o estabelecimento de estratégias é o departamento de futebol que, dentro da estrutura organizacional de um clube, é responsável pelo gerenciamento de atividades ligadas à contratação de jogadores, vendas, empréstimos de atletas, parcerias, bem como, o acompanhamento da comissão técnica e dos atletas nas diferentes competições disputadas.

Fica evidente que apenas a utilização de estratégias de suporte não significa que ocorrerão processos de aprendizagem entre os membros de um time de futebol. A aprendizagem individual, o alinhamento de valores entre os atletas e comissão técnica e aspectos ligados à motivação dos jogadores, por exemplo, também são fatores contribuintes para a realização de tal fenômeno psicológico.

Sugere-se a realização de pesquisas de campo em clubes de futebol sobre o tema em questão para que sejam apresentadas evidências empíricas que possam corroborar ou confrontar os indícios apresentados por meio deste ensaio teórico.

O presente estudo não é conclusivo, porém, traz fundamentos teóricos e algumas pesquisas empíricas que demonstram a existência de estruturas organizacionais nos clubes de futebol que podem facilitar os processos de aprendizagem entre os jogadores e a comissão técnica. Com isso, será possível compreender que os clubes também podem se tornar organizações de aprendizagem e, consequentemente, usufruir das características positivas que tipo de gestão apresenta.

\section{Referências bibliográficas}

ABBAD, G.S. \& BORGES-ANDRADE, J.E. Aprendizagem humana em organizações de trabalho. In: ZANELLI, J.C.; BORGES-ANDRADE, J.E. \& BASTOS, A.V.B. (Orgs.) Psicologia, organizações e trabalho no Brasil. Pp. 237-75. Porto Alegre: Artmed, 2004.

ANTONELLO, C.S. Articulação da aprendizagem formal e informal: seu impacto no desenvolvimento de competências gerenciais. Alcance, Itajaí, 12 (2): 183-209, 2005.

ARGYRIS, C. \& SCHÖN, D. Organizational learning: a theory of action perspective. Reading Mass: Addison-Wesley, 1978.

BALDUCK, A. \& BUELENS, M. Does sacking the coach help or hinder the team in the short term? Evidence from Belgian soccer. Working Paper of Ghent University, Belgium. n. 430, Jan/2007. 
BASTOS, A.V.B.; GONDIM, S.N.G. \& LOIOLA, E. Aprendizagem organizacional versus organizações que aprendem: características e desafios que cercam essas duas abordagens de pesquisa. Revista de Administração da USP, 39(3): 220-30, 2004.

BRUNORO, J.C. \& AFIF, A. Futebol 100\% profissional. São Paulo: Gente, 1997.

CARVALHO, A.V. Aprendizagem organizacional em tempos de mudança. São Paulo: Pioneira, 1999.

CORRÊA, D.K.A; ALCHIERI, J.C.; DUARTE, L.R.S. \& STREY, M.N. Excelência na produtividade: a performance dos jogadores de futebol profissional. Psicologia: reflexão e crítica, 15(2), 2002.

CORREAA, D.K.A. A construção de competências coletivas em equipes esportivas: o caso do futebol. Dissertação (Mestrado em Administração) Universidade Federal do Rio Grande do Sul, Porto Alegre, 2004.

DAMO, A.S. Dom, amor e dinheiro no futebol de espetáculo. Revista Brasileira de Ciências Sociais, 23(66): 139-50, 2008.

DE GEUS, A. A empresa viva: como as organizações podem aprender a prosperar e se perpetuar. Rio de Janeiro: Campus, 1998.

EASTERBY-SMITH, M. \& ARAUJO, L. Aprendizagem organizacional: oportunidades e debates atuais. In: EASTERBY-SMITH, M.; BURGOYNE, J. \& ARAUJO, L. (Coords.) Aprendizagem organizacional e organização de aprendizagem. São Paulo: Atlas, 2001.

FINGER, M. \& BRAND, S.B. Conceito de "organização de aprendizagem" aplicado à transformação do setor público: contribuições conceituais ao desenvolvimento da teoria. In: EASTERBY-SMITH, M.; BURGOYNE, J. \& ARAUJO, L. (Coords.) Aprendizagem organizacional e organização de aprendizagem. São Paulo: Atlas, 2001.

FRANCO, M.J.B. \& FERREIRA, T.S.C. Um estudo de caso sobre as organizações que aprendem. Comportamento organizacional e gestão, 13(2): 169-89, 2007.

GARVIN, D. A. Building a learning organization. Harvard Business Review, Jul-Ago/1993.

GARVIN, D. A. Aprendizagem em ação: um guia para transformar sua empresa em uma learning organization. Rio de Janeiro: Qualitymark, 2002. 
GARVIN, D.A.; EDMONSON, A.C. \& GINO, F. Is yours a learning organization? Harvard Business Review, Março/2008.

GOHN, M.G. Educação não-formal, participação da sociedade civil e estruturas colegiadas nas escolas. Ensaio: avaliação e políticas públicas em educação, 14(50), Rio de Janeiro: Jan-Mar/2006.

KIEHL, J. Learning to change: organizational learning and knowledge transfer. Saarbrücken: VDM, 2008.

KIM, D.H. O elo entre a aprendizagem individual e a aprendizagem organizacional. In: KLEIN, D.A. (Ed.). A gestão estratégica do capital intelectual: recursos para a economia baseada em conhecimento. Rio de Janeiro: Qualitymark, 1998.

KOLB, D.A. Experiential learning: experience as the source of learning and development. New Jersey: Prentice-Hall, 1984.

LEONCINI, M.P. \& SILVA, M.T. Entendendo o futebol como um negócio: um estudo exploratório. Gest. Prod. 12 (1), Abril/2005.

MALCOLM, J.; HODKONSON, P. \& COLLEY, H. The interrelationships between informal and formal learning. Journal of Workplace Learning. Bingley, 15(7/8): 313-18, 2003.

MORAES, L.C.; RABELO, A.S. \& SALMELA, J.H. Papel dos pais no desenvolvimento de jovens futebolistas. Psicol. Reflex. Crit., 17(2), 2004.

MOSCOVICI, F. Desenvolvimento interpessoal: treinamento em grupo. $10^{\mathrm{a}}$ Edição. Rio de Janeiro: José Olympio, 2001.

RELATÓRIO FINAL DO FÓRUM DE DISCUSSÃO PERMANENTE DE POLÍTICAS DO ESPORTE. São Paulo: Fundação Getúlio Vargas, 2004.

RIGGENBACH, D. Percepções de empregados de uma organização não governamental sobre a aprendizagem individual no contexto de trabalho. Dissertação (Mestrado em Psicologia) - Universidade Federal de Santa Catarina, Florianópolis, 2007.

SENGE, P. A dança das mudanças: os desafios de manter o crescimento e o sucesso em organizações que aprendem. $8^{a}$ Edição. Rio de Janeiro: Elsevier, 1999.

SENGE, P. A quinta disciplina: arte e prática da organização que aprende. $10^{a}$ Edição. São Paulo: Best Seller, 2002. 
SCHUGURENSKY, D. The forms of informal learning: towards a conceptualization of the field. Centre of the study of education and work. NALL Working Papers, Toronto. n.19, 2000.

SILVA, N. As interfaces entre cultura e aprendizagem organizacional: o caso de uma empresa do setor cerâmico de Santa Catarina. Tese (Doutorado em Engenharia de Produção) - Universidade Federal de Santa Catarina, Florianópolis, 2001.

SZEZERBICKI, A.S. et al. A gestão do conhecimento em equipes de alta performance: o caso do Clube Atlético Paranaense. Publicações da UEPG, 14(1): 55-61, Jun/2006.

TSANG, E.W.K. Organizational learning and the learning organization: a dichotomy between descriptive and prescriptive research. Human Relations, 50(1): 73-89, Jan/1997.

ZANELLI, J.C. \& SILVA, N. Interação humana e gestão: a construção psicossocial das organizações de trabalho. São Paulo: Casa do Psicólogo, 2008.

ZOUAIN, D.M; ALVES, J.A.B. \& PIERANTI, O.P. Relatório final de atividades do Fórum de Discussão Permanente de Políticas de Esporte. Revista de Administração Pública, 40 (4), 2006. 